\title{
Real-World Use Of Ultrathin-Strut Biodegradable Polymer-Coated Sirolimus-Eluting Stents In Patients With Coronary Artery Disease: 6-Month Clinical
} Outcomes

This article was published in the following Dove Press journal:

Vascular Health and Risk Management

\section{Prakash Ajmera' \\ Ramesh Pothineni ${ }^{2}$ \\ Kamal Kumar Chawla' \\ Sai Sudhakar Mantravadi ${ }^{3}$ \\ Pankaj Vinod Jariwala (iD) \\ Vinod Vijan ${ }^{5}$ \\ Vikrant Vijan ${ }^{5}$ \\ 'Department of Cardiology, Malla Reddy Narayana Multispeciality Hospital, Hyderabad, Telangana 500055, India; ${ }^{2}$ Department of Cardiology, Ramesh Hospitals, Vijayawada, Andhra Pradesh 520008, India; ${ }^{3}$ Department of Cardiology, Gleneagles Global Hospital, Hyderabad, Telangana 500004, India; ${ }^{4}$ Department of Cardiology, Yashoda Hospitals, Somajiguda, Hyderabad, Telangana, 500082, India; ${ }^{5}$ Department of Cardiology, Vijan Cardiac and Critical Care Centre, Nashik, Maharashtra 422005, India}

Correspondence: Prakash Ajmera Malla Reddy Narayana Multispeciality Hospital, I-I-2I6 Suraram Crossroads, Jeedimetla, Hyderabad, Telangana 500055, India

Tel +91 9985401317

Emailwglprakash@yahoo.com
Background: Although a number of drug-eluting stents have been developed with different design, composition, and polymers, the search for an ideal drug-eluting stent is ongoing. The Tetriflex (Sahajanand Medical Technology, Surat, India) is a newer-generation, ultrathin $(60 \mu \mathrm{m})$ biodegradable polymer-coated sirolimus-eluting stent (SES) designed with a unique long dual Zlink on a cobalt-chromium alloy. The present registry aimed to evaluate the safety and clinical outcomes of the Tetriflex SES at 6-month post-implantation.

Methods: This was an investigator-initiated, retrospective, multicenter, single-arm, observational registry conducted at five tertiary-care centers in India. A total of 1,269 consecutive patients with coronary artery disease who underwent implantation of at least one Tetriflex SES between March 2017 and March 2018 were included. The primary outcome was considered a composite of cardiac death, myocardial infarction and target-lesion revascularization (TLR) at 6-month follow-up. Stent thrombosis was evaluated as a safety outcome at 6-month follow-up. Results: The mean age of patients was $54.99 \pm 10.80$ years. Among 1,515 lesions treated with 1,682 Tetriflex SES, 58.3\% were type C lesions. Six-month follow-up was done for 1,245 of 1,269 (98.1\%) patients. At 6 months, composite events had occurred in 31 (2.5\%) patients, consisting of ten $(0.8 \%)$ cardiac deaths, $16(1.3 \%)$ myocardial infarctions, and five $(0.4 \%)$ TLRs. Stent thrombosis was observed in seven $(0.56 \%)$ cases at 6 months. A subgroup analysis between diabetic and nondiabetic patients did not reveal any statistically significant difference for clinical outcomes at 6-month follow-up.

Conclusion: The results of the current registry outline the safety and effectiveness of the Tetriflex SES in real-world patients, as it displayed favorable clinical outcomes at 6-month follow-up, with low incidence of TLR and stent thrombosis.

Keywords: biodegradable polymer, drug-eluting stents, sirolimus, ultrathin strut

\section{Introduction}

With the beginning of the 21 st century, the era of drug-eluting stents (DESs) was instigated as a novel discovery in the world of interventional cardiology. Favorably, DESs to a certain extent have overcome the complications of bare-metal stents, as they reduce the restenosis rate and need for revascularization. ${ }^{1-4}$ However, incidents of restenosis were still noted, in addition to the higher rate of late stent thrombosis with DESs. ${ }^{5,6}$ It has been well established that not only patient and lesion characteristics but also stent platform, drugs, polymers, strut thickness, type 
of coating, and stent design play a key role in deciding the safety and effectiveness of coronary stents. ${ }^{7-10}$ Therefore, the development of DESs has evolved from durable polymers to biodegradable polymers for controlled drugrelease kinetics, from stainless steel to cobalt-chromium (Co-Cr) and a platinum-chromium stent platform, and from thick to ultrathin struts with better stent designs. Although newer-generation DESs with biodegradable polymer coating and ultrathin struts have been developed with different design and composition, the search for an ideal newer-generation biodegradable polymer-coated DES is ongoing.

The Tetriflex (Sahajanand Medical Technology, Surat, India), a latest-generation ultrathin $(60 \mu \mathrm{m})$ biodegradable polymer-coated sirolimus-eluting stent (SES), uses $\mathrm{Co}-\mathrm{Cr}$ as the stent platform. The stent was designed with a unique long dual Z-link (LDZ-link) and in-phase struts. The surface of the stent has multilayered conformal coating comprised of hydrophilic and hydrophobic polymers in combination for controlled and sustained release of sirolimus. The clinical performance of the Tetriflex SES has not been published anywhere yet. Therefore, the present registry aimed to evaluate the safety and clinical outcomes of the Tetriflex SES in unselected, real-world patients with coronary artery disease (CAD).

\section{Methods}

\section{Study Design And Participants}

This was an investigator-initiated, retrospective, multicenter, single-arm, observational registry carried out at five tertiary-care centers in India. A total of 1,269 consecutive CAD patients (aged $\geq 18$ years) who underwent implantation of at least one Tetriflex SES between March 2017, and March 2018 were included in this registry. The registry strictly obeyed the principles of good clinical practice and Declaration of Helsinki, and was approved by the Institutional Ethics Committee, Dr Ramesh Cardiac and Multispecialty Hospital (ECR/81/ INST/AP/2013/RR/2016). At the time of the index procedure, written informed consent for percutaneous coronary intervention and use of properly anonymized clinical data was obtained from patients or from patient designees.

\section{Description Of Study Stent}

The Tetriflex SES (Tetrinium L605) is a latest-generation ultrathin $(60 \mu \mathrm{m})$ biodegradable polymer-coated, $\mathrm{Co}-\mathrm{Cr}$ coronary stent designed with unique LDZ-link and inphase struts. Detailed characteristics of the Tetriflex SES are given in Table 1. The multilayer conformal coating on surface of the Tetriflex stent contains a blend of sirolimus and biodegradable polymeric matrix comprising a combination of hydrophilic and hydrophobic polymers containing poly-L-lactide, 50/50 poly(D,L-lactide-co-glycolide), and polyvinyl pyrrolidone. These polymers give an elastomeric property to the coating in line with the metalexpansion mechanism and control drug elution from the stent coating. The coating matrix offers good coating adhesion with the stent surface. The multilayer coating technology offers controlled drug release to accommodate arterial drug requirements post-stent implantation. Further, the unique blend of biodegradable polymers in each layer aids in achieving controlled drug release and offers unmatched coating integrity. Figure 1 displays the release profile of drug from the Tetriflex SES. In addition, the drug-free top layer composed of hydrophilic polymers with antioxidants tends to improve product shelf life and protect coating layers during implantation. Scanning

Table I Characteristics Of Tetriflex Drug-Eluting Stent

\begin{tabular}{|c|c|}
\hline Characteristic & Tetriflex Stent \\
\hline $\begin{array}{l}\text { Available stent lengths } \\
(\mathrm{mm})\end{array}$ & $8,12,16,20,24,28,32,36,40,44,48$ \\
\hline $\begin{array}{l}\text { Available stent } \\
\text { diameters }(\mathrm{mm})\end{array}$ & $2.00,2.25,2.50,2.75,3.00,3.50,4.00,4.50$ \\
\hline Stent material & L605 Co-Cr alloy \\
\hline Stent design & $\begin{array}{l}\text { Laser cut from seamless tubing in a } \\
\text { serpentine pattern }\end{array}$ \\
\hline Stent platform & Tetrinium \\
\hline Stent-strut dimension & Thickness $60 \mu \mathrm{m}$ \\
\hline Drug & Sirolimus $\left(1.4 \mu g / \mathrm{mm}^{2}\right)$ \\
\hline Polymer type & $\begin{array}{l}\text { Biodegradable polymer } \\
\text { Combination of hydrophilic and } \\
\text { hydrophobic polymers: } \\
\text { - poly-L-lactide } \\
\text { - } 50 / 50 \text { poly(D,L-lactide-co-glycolide) } \\
\text { - polyvinyl pyrrolidone }\end{array}$ \\
\hline Drug-release profile & $\begin{array}{l}80 \% \text { sirolimus release in I month } \\
\text { Remaining releases slowly within } 3 \text { months }\end{array}$ \\
\hline $\begin{array}{l}\text { Average coating } \\
\text { thickness }\end{array}$ & $4-6 \mu \mathrm{m}$ \\
\hline Guiding catheter & 5F-compatible (minimum) \\
\hline
\end{tabular}


In vitro cumulative drug release (\%)

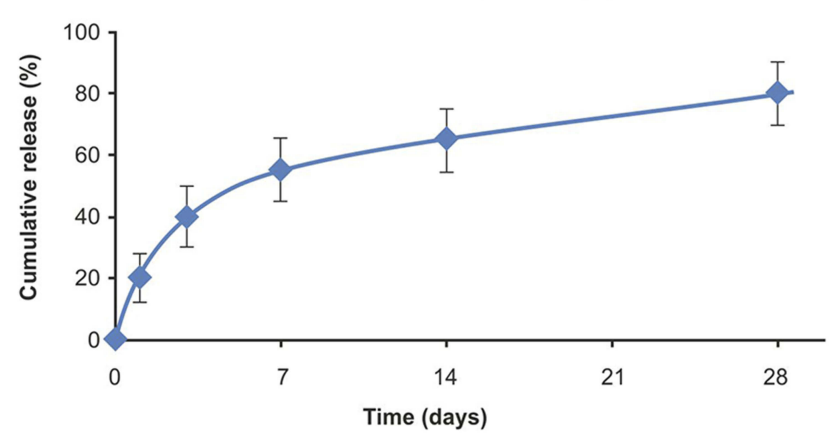

Figure I In vitro sirolimus-release profile of Tetriflex stent.

electron microscopy of the sterile crimped stent and expanded stent are depicted in Figure 2, showing a smooth and uniform coating surface without any coating anomalies or defects, such as webbing, bridging, or strut-to-strut contact, even after expansion of the stent.

\section{Coronary Intervention And Adjuvant Medications}

The interventional procedure was performed according to the manufacturer's instructions for use provided with the Tetriflex SES and institutional standard practice. Before the interventional procedure, all patients received a loading dose of aspirin (150-300 mg) and clopidogrel (600 $\mathrm{mg}$ ), or prasugrel (60 mg), or ticagrelor (two tablets of 90 mg each). During the procedure, all patients received heparin or bivalirudin, whereas use of glycoprotein IIb/ IIIa inhibitors was done as per investigator preference. After the procedure, dual-antiplatelet therapy was recommended for at least 12 months (aspirin 75-100 mg and clopidogrel $75 \mathrm{mg}$ daily, or prasugrel $10 \mathrm{mg}$ daily, or ticagrelor $90 \mathrm{mg}$ twice daily), followed by aspirin monotherapy ad infinitum.

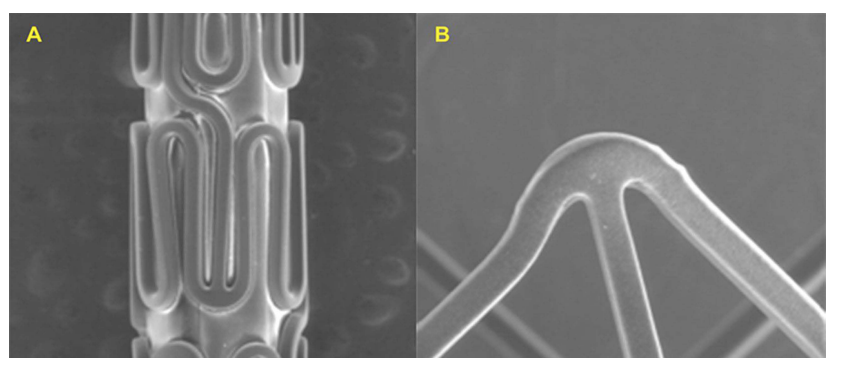

Figure 2 Scanning electron microscopy: (A) crimped Tetriflex SES; (B) expanded Tetriflex SES.

\section{Data Collection And Follow-Up}

Baseline clinical data, lesion and procedural characteristics, and in-hospital clinical outcomes were consecutively extracted from individual hospital medical records. Follow-up at 30 days and 6 months of the index coronary intervention was received via clinical follow-up or telephone contact.

\section{Study Outcomes And Definitions}

The primary outcome of the registry was a composite event rate of cardiac death, myocardial infarction (MI), and targetlesion revascularization (TLR) at 6 months. Any death due to a cardiac cause (such as MI, low-output failure, lethal arrhythmia), unwitnessed death, death of unknown reason, and all procedure-related deaths linked to concomitant treatment was stated as cardiac death, whereby noncardiac death included any death where a noncardiac cause was well established. MI was defined according to the third universal definition by the European Society of Cardiology and American College of Cardiology Foundation. ${ }^{11}$ TLR was defined as repeat revascularization percutaneously or surgically to the lesion anywhere within the stent or subsequent $5 \mathrm{~mm}$ of distal or proximal segment to the stent. A non-target lesion target-vessel revascularization was considered when there was stenosis in any segment of the treated vessel other than a treated lesion. During follow-up, stent thrombosis, defined as per the Academic Research Consortium, was evaluated as a safety outcome. ${ }^{12}$

\section{Statistical Analysis}

All data were analyzed using statistical software SPSS 20. Means \pm SD were used to present continuous variables. Categorical variables were presented as frequencies and percentages, and were compared using $\chi^{2}$ or Fisher's exact test. $P<0.05$ was considered statistically significant. A Kaplan Meier method was used to estimate cumulative composite event-free survival at 6-month follow-up.

\section{Results}

\section{Baseline Demographic And Clinical Characteristics}

The mean age of the patients was $54.99 \pm 10.80$ years, with $910(71.7 \%)$ male patients, 622 (49.0\%) hypertensive, 465 (36.6\%) diabetic, 370 (29.2\%) with hypercholesterolemia, and $218(17.2 \%)$ smokers. Forty (3.2\%) patients were presented with cardiogenic shock. Demographic details and clinical presentation of all patients are given in Table 2. 


\section{Lesion Characteristics And Procedure Details}

Lesion characteristics are delineated in Table 3. In sum, $613(48.3 \%)$ patients were diagnosed with single-vessel disease, $536(42.2 \%)$ double-vessel disease, and 120 $(9.5 \%)$ triple-vessel disease. The most common diseased vessel was the left anterior descending artery (47.7\%). Among 1,515 lesions, 222 (14.7\%) were totally occluded, of which $131(8.6 \%)$ were chronic total occlusions. Of the lesions, $58.3 \%(\mathrm{n}=883)$ were type C. Among all patients, $1,095(86.3 \%)$ were accessed via the femoral artery and $174(13.7 \%)$ via the radial artery. A total of 1,682 stents of different dimensions were implanted to treat the 1,515 lesions. Mean stent length and stent diameter were 25.15 $\pm 8.83 \mathrm{~mm}$ and $2.89 \pm 0.32 \mathrm{~mm}$, respectively. Table 4 highlights the procedural and stent details. Procedural success was achieved in $98.7 \%$ of patients. During the procedure, no incidence of bleeding or coronary artery dissection was observed.

\section{Clinical Outcomes}

At 6-month, the primary outcome had occurred in 31 patients $(2.49 \%)$ : ten $(0.8 \%)$ cardiac death, $16(1.29 \%)$

Table 2 Baseline Characteristics For 1,269 Patients Implanted With the Tetriflex SES

\begin{tabular}{|c|c|}
\hline Characteristics & $\begin{array}{l}\text { Number Of Patients } \\
(n=1269)\end{array}$ \\
\hline $\begin{array}{l}\text { Age (years), mean } \pm \text { SD } \\
\text { Male, n (\%) }\end{array}$ & $\begin{array}{l}54.99 \pm 10.80 \\
910(71.7 \%)\end{array}$ \\
\hline $\begin{array}{l}\text { Cardiovascular risk } \\
\text { Hypertension, n (\%) } \\
\text { Diabetes mellitus, n (\%) } \\
\text { Hypercholesterolemia, n (\%) } \\
\text { Smoking, n (\%) } \\
\text { Previous MI, n (\%) } \\
\text { Previous PCl, n (\%) } \\
\text { Previous CABG, n (\%) } \\
\text { Previous stroke, n (\%) } \\
\text { Renal insufficiency, n (\%) } \\
\text { Family history of CAD, n (\%) } \\
\text { Cardiogenic shock, n (\%) }\end{array}$ & $\begin{array}{l}622(49.0 \%) \\
465(36.6 \%) \\
370(29.2 \%) \\
218(17.2 \%) \\
136(10.7 \%) \\
89(7.0 \%) \\
23(1.8 \%) \\
26(2.0 \%) \\
17(1.3 \%) \\
32(2.5 \%) \\
40(3.2 \%)\end{array}$ \\
\hline $\begin{array}{l}\text { Clinical presentation } \\
\text { Stable angina, n (\%) } \\
\text { Unstable angina, n (\%) } \\
\text { ST-elevation MI, n (\%) } \\
\text { Non-ST-elevation MI, n (\%) }\end{array}$ & $\begin{array}{l}336(26.5 \%) \\
364(28.7 \%) \\
398(31.4 \%) \\
171(13.5 \%)\end{array}$ \\
\hline
\end{tabular}

Abbreviations: $\mathrm{MI}$, myocardial infarction; $\mathrm{PCl}$, percutaneous coronary intervention; $C A B G$, coronary artery-bypass graft; $C A D$, coronary artery disease.
Table 3 Lesion Characteristics For 1,269 Patients Implanted With the Tetriflex SES

\begin{tabular}{|c|c|}
\hline Characteristics & \\
\hline Lesions, $\mathbf{n}$ & $\mathrm{I}, 5 \mathrm{I} 5$ \\
\hline \multicolumn{2}{|l|}{ Vessel involvement ( 1,269 patients) } \\
\hline Single-vessel disease, $\mathrm{n}(\%)$ & $613(48.3 \%)$ \\
\hline Double-vessel disease, n (\%) & $536(42.2 \%)$ \\
\hline Triple-vessel disease, n (\%) & $120(9.5 \%)$ \\
\hline \multicolumn{2}{|l|}{ Target coronary artery ( $(, 5$ I 5 lesions) } \\
\hline Left main, n (\%) & $5(0.3 \%)$ \\
\hline Left anterior descending artery, $\mathrm{n}(\%)$ & $723(47.7 \%)$ \\
\hline Left circumflex artery, n (\%) & $31 \mathrm{I}(20.5 \%)$ \\
\hline Right coronary artery, n (\%) & $470(31.0 \%)$ \\
\hline Saphenous vein graft, $\mathrm{n}(\%)$ & $6(0.4 \%)$ \\
\hline \multicolumn{2}{|l|}{ Lesion details ( 1,5 I 5 lesions) } \\
\hline Type A, n (\%)* & $206(13.6 \%)$ \\
\hline Type BI, n (\%)* & $200(13.2 \%)$ \\
\hline Type B2, n (\%)* & $226(14.9 \%)$ \\
\hline Type C, n (\%)* & $883(58.3 \%)$ \\
\hline Total occlusion, n (\%) & $222(14.7 \%)$ \\
\hline Chronic total occlusion & $|3|(8.6 \%)$ \\
\hline
\end{tabular}

Note: *According to American College of Cardiology-American Heart Association lesion-morphology criteria.

MI, and five (0.4\%) TLR. Non-target lesion target-vessel revascularization had occurred in two $(0.16 \%)$ patients at 6 months. In Figure 3, a Kaplan-Meier curve of the eventfree survival rate for the composite end point at 6 months is presented. Seven cases $(0.56 \%)$ of stent thrombosis were reported at 6 months: two $(0.16 \%)$ definite stent thrombosis, two $(0.06 \%)$ probable stent thrombosis, and three $(0.24 \%)$ possible stent thrombosis. Table 5 displays the clinical outcomes of Tetrifelx SES at 30-day and 6-month follow-up. Subgroup analysis between diabetic and nondiabetic patients did not reveal any statistically significant difference for 6-month clinical outcomes (Figure 4).

\section{Discussion}

Since the introduction of DESs, they have been continually refined in terms of stent design and composition, strut thickness, polymers, and coating thickness in an attempt to achieve better safety and efficacy. The Tetriflex SES, used in the present registry, is a latest-generation ultrathin $(60 \mu \mathrm{m})$ biodegradable polymer-coated DES designed with unique coating and LDZ-link on a Co-Cr alloy. This registry demonstrated positive evidence of safety and clinical performance of the Tetriflex SES in real-world patients at 6-month follow-up. 
Table 4 Procedural Characteristics For I,269 Patients Implanted With the Tetriflex SES

\begin{tabular}{|l|l|}
\hline Characteristics & \\
\hline Stent details & \\
Total stents, $\mathrm{n}$ & $\mathrm{I}, 682$ \\
Stents deployed per patient, mean $\pm \mathrm{SD}$ & $1.23 \pm 0.45$ \\
Stents deployed per lesion, mean $\pm \mathrm{SD}$ & $1.1 \mathrm{I} \pm 0.33$ \\
Stent length (mm), mean \pm SD & $25.15 \pm 8.83$ \\
Stent diameter (mm), mean $\pm \mathrm{SD}$ & $2.89 \pm 0.32$ \\
\hline Stent length & \\
$8 \mathrm{~mm}, \mathrm{n}(\%)$ & $8(0.5 \%)$ \\
$12 \mathrm{~mm}, \mathrm{n}(\%)$ & $134(8.0 \%)$ \\
$16 \mathrm{~mm}, \mathrm{n}(\%)$ & $255(15.2 \%)$ \\
$20 \mathrm{~mm}, \mathrm{n}(\%)$ & $293(17.4 \%)$ \\
$24 \mathrm{~mm}, \mathrm{n}(\%)$ & $287(17.1 \%)$ \\
$28 \mathrm{~mm}, \mathrm{n}(\%)$ & $234(13.9 \%)$ \\
$32 \mathrm{~mm}, \mathrm{n}(\%)$ & $201(12.0 \%)$ \\
$36 \mathrm{~mm}, \mathrm{n}(\%)$ & $\mathrm{I}(4(6.8 \%)$ \\
$40 \mathrm{~mm}, \mathrm{n}(\%)$ & $74(4.4 \%)$ \\
$44 \mathrm{~mm}, \mathrm{n}(\%)$ & $47(2.8 \%)$ \\
$48 \mathrm{~mm}, \mathrm{n}(\%)$ & $35(2.1 \%)$ \\
\hline Stent diameter & \\
$2.25 \mathrm{~mm}, \mathrm{n}(\%)$ & $6(0.4 \%)$ \\
$2.50 \mathrm{~mm}, \mathrm{n}(\%)$ & $386(22.9 \%)$ \\
$2.75 \mathrm{~mm}, \mathrm{n}(\%)$ & $463(27.5 \%)$ \\
$3.00 \mathrm{~mm}, \mathrm{n}(\%)$ & $573(34.1 \%)$ \\
$3.50 \mathrm{~mm}, \mathrm{n}(\%)$ & $253(15.0 \%)$ \\
$4.00 \mathrm{~mm}, \mathrm{n}(\%)$ & $\mathrm{I}(0.1 \%)$ \\
\hline
\end{tabular}

Strut thickness has a great impact on stent thrombogenicity and restenosis during the early phase of stent implantation. . $^{13,14}$

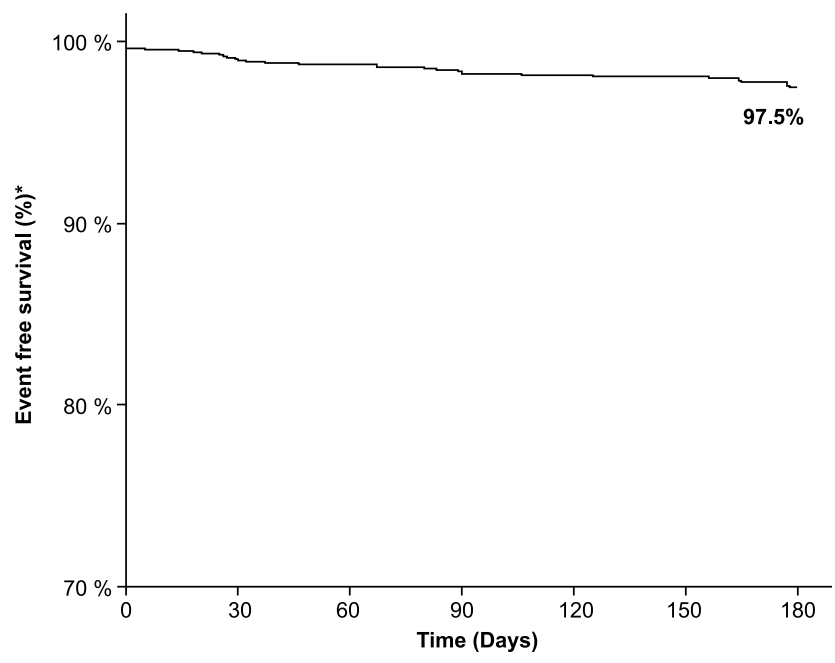

Figure 3 Cumulative composite event-free survival at 6-month follow-up. (*Composite events comprise of cardiac death, myocardial infarction and target lesion revascularization).
Furthermore, the lack of complete strut coverage and optimal healing have been strongly associated with the incidence of late stent thrombosis. ${ }^{7,15-17}$ However, various studies have reported that thinner struts provide rapid healing and complete endothelial coverage, which may reduce the risk of thrombus formation. ${ }^{14,18}$ A recent meta-analysis also confirmed that DESs with thinner struts have significant associations with reduced risk of stent thrombosis and MI compared to thicker-strut DESs. ${ }^{19}$

It has also been found that thinner struts reduce the extent of injury to the vessel wall during stent implantation, which reduces the risk of restenosis compared to thick struts. ${ }^{20}$ The ISAR-STEREO $^{21}$ and ISAR-STEREO- ${ }^{22}$ trials compared the association of thin-strut stents $(50 \mu \mathrm{m})$ and thick-strut stents $(140 \mu \mathrm{m})$ with restenosis. The results of both trials demonstrated that thinner-struts stent reduced the clinical and angiographic restenosis compared to thicker-strut stents. ${ }^{21,22}$ The improved flexibility and deliverability, lowered crimped profile, reduced blood-flow disturbance, lowered injury to arterial wall, reduced risk of acute/chronic inflammation, faster re-endothelialization and early coverage, and quick and better healing quality offered by ultrathin struts collectively improved the clinical outcomes of the previous studies and the current registry. ${ }^{20,23,24}$

After complete drug release, permanent polymers cause chronic inflammation in the vessel wall, delay vascular healing, and trigger hypersensitivity reactions that lead to local arterial injury and ultimately result into late and very late stent thrombosis. ${ }^{5,25}$ As such, there have always been safety concerns with earlier-generation permanent polymer-coated DESs. With the aim of overcoming these limitations, biodegradable polymer-coated DESs have been developed. Various studies and meta-analyses have established that biodegradable polymer-coated DESs have overcome or achieved comparable results in terms of stent thrombosis and other clinical outcomes compared to durable-polymer DESs. ${ }^{26-34}$ Therefore, in addition to ultrathin struts of the Tetriflex SES, a blend of hydrophilic and hydrophobic biodegradable polymers that provide controlled-release kinetics of sirolimus also has probably contributed toward improved clinical outcomes in the present registry.

The present registry included $49 \%$ hypertensive patients, $36.6 \%$ diabetic patients, and 58\% type $\mathrm{C}$ lesions, which displays the complexity of the patients. The Tetriflex SES is designed with a unique LDZ-link with long connectors, which provide excellent trackability and better push force through complex lesions and ease of handling the tortuous path of coronary arteries. It also has an in-phase strut design, 
Table 5 In-Hospital, 30-Day, And 6-Month Clinical Outcomes Of Patients Implanted With the Tetriflex SES

\begin{tabular}{|c|c|c|c|}
\hline Clinical Outcomes & $\begin{array}{l}\text { In-Hospital } \\
(n=\mid 269)\end{array}$ & $\begin{array}{l}\text { At 30-Day Follow-Up } \\
(n=1269)\end{array}$ & $\begin{array}{l}\text { At 6-Month Follow-Up } \\
(n=\mid 245,98.1 \%)\end{array}$ \\
\hline Death from any cause, $\mathrm{n}(\%)$ & $2(0.16 \%)$ & $6(0.47 \%)$ & $15(1.20 \%)$ \\
\hline Cardiac death, n (\%) & $2(0.16 \%)$ & $4(0.32 \%)$ & $10(0.80 \%)$ \\
\hline Noncardiac death, n (\%) & 0 & $2(0.16 \%)$ & $5(0.40 \%)$ \\
\hline MI, n (\%) & $2(0.16 \%)$ & $10(0.79 \%)$ & $16(1.30 \%)$ \\
\hline TLR, n (\%) & 0 & I $(0.08 \%)$ & $5(0.40 \%)$ \\
\hline Non-TL-TVR, n (\%) & 0 & I $(0.08 \%)$ & $2(0.16 \%)$ \\
\hline Overall stent thrombosis, $\mathrm{n}(\%)^{*}$ & $2(0.16 \%)$ & $4(0.32 \%)$ & $7(0.56 \%)$ \\
\hline Definite stent thrombosis, $\mathrm{n}(\%)$ & $2(0.16 \%)$ & $2(0.16 \%)$ & $2(0.16 \%)$ \\
\hline Probable stent thrombosis, $\mathrm{n}(\%)$ & 0 & $2(0.16 \%)$ & $2(0.16 \%)$ \\
\hline Possible stent thrombosis, $\mathrm{n}(\%)$ & 0 & 0 & $3(0.24 \%)$ \\
\hline Composite events (cardiac death, MI, and TLR), n (\%) & $4(0.32 \%)$ & $15(1.18 \%)$ & $31(2.50 \%)$ \\
\hline
\end{tabular}

Note: *According to Academic Research Consortium.

Abbreviations: MI, myocardial infarction; TLR, target-lesion revascularization; non-TL-TVR, non-target lesion target-vessel revascularization.

which aids flexibility and provides better structural support. Along with ultrathin struts, these stent characteristics enhance overall stent integrity and radial strength and resist longitudinal stent compression, ultimately making the Tetriflex SES a suitable stent to handle complex coronary lesions. ${ }^{6,23}$ Another positive practical advantage of the Tetriflex SES is its availability in a wide range of sizes (diameter $2.0-4.5 \mathrm{~mm}$ and length $8-48 \mathrm{~mm}$ ). This avoids the use of undersized/oversized stents, need of stent overlapping for long lesions and related technical/procedural challenges, underexpansion/overexpansion of stents, and offers the best immediate result with the lowest-possible complication rate. A case depicting successful deployment of the Tetriflex SES in a tortuous vessel, ie, right coronary artery-posterior descending artery, is displayed in

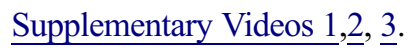

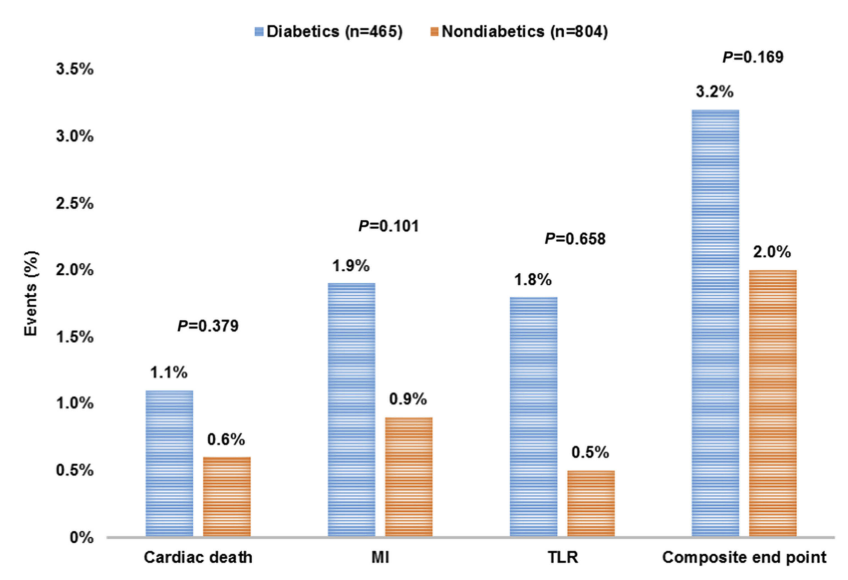

Figure 4 Comparison of 6-month clinical outcomes between diabetic and nondiabetic patients. (MI: myocardial infarction and TLR: target lesion revascularization).
At 6 months, the present registry demonstrated 2.5\% composite events, comprising $0.8 \%$ cardiac death, $1.3 \% \mathrm{MI}$, and $0.4 \%$ TLR. Similarly, in the FLEX registry Lemos et al reported 2.2\% major adverse cardiac events at 6-month follow-up with Supraflex SES. ${ }^{17}$ Furthermore, the CREDIT-III trails on the Excel 2 biodegradable polymer-coated, thinstruts $(88 \mu \mathrm{m})$ DES reported 5\% target-lesion failure and $0.1 \%$ TLR at 6 months. ${ }^{35}$ All these observations are comparable with the findings of the present registry (Table 6). Further, the X-SEARCH registry reported $9.2 \%$ major adverse cardiac events for the Xience everolimus-eluting stent at 6 months. ${ }^{36}$ In addition, a registry on the Synergy everolimus-eluting stent also demonstrated $4.2 \%$ target-lesion failure at 6 months. ${ }^{37}$ Furthermore, in line with previous studies, the present registry also reported similar incidence of stent thrombosis, even though it comprised a complex population (Table 6). Post hoc analysis of the present registry found no significant differences in clinical outcomes between diabetic and nondiabetic patients. However, a large-scale study should be conducted to prove this, as the results may be considered exploratory.

Several biodegradable polymer-coated DESs with varied strut thickness (thin to ultrathin) are available, yet the search for an ideal biodegradable polymer-coated DES goes on. With its novel design, unique three-layer biodegradable-polymer coating, and ultrathin struts $(60 \mu \mathrm{m})$ for all sizes, and favorable clinical outcomes at 6-month follow-up, the Tetriflex SES could be proposed as a choice of biodegradable polymer-coated DES after long-term follow-up.

Although this registry reports favorable results, it has several limitations. First, this was a retrospective and 
Table 6 Six-Month Clinical Outcomes Of Standard Biodegradable Polymer DESs And Durable Polymer DESs In Various Studies And Of the Tetriflex SES In Present Study

\begin{tabular}{|c|c|c|c|c|c|c|c|c|}
\hline \multirow[t]{2}{*}{ Stents } & \multirow[t]{2}{*}{ Polymers } & \multirow[t]{2}{*}{ Platform } & \multirow{2}{*}{$\begin{array}{l}\text { Strut Thickness } \\
(\mu \mathrm{m})\end{array}$} & \multirow[t]{2}{*}{ Study/Database } & \multicolumn{4}{|c|}{ Events At 6 Months Follow-Up } \\
\hline & & & & & TLF/ MACE & TLR & MI & ST \\
\hline Tetriflex & Biodegradable & $\mathrm{Co}-\mathrm{Cr}$ & 60 & Present study & $\begin{array}{l}2.5 \% \text { composite } \\
\text { events }\end{array}$ & $0.40 \%$ & $1.30 \%$ & $0.56 \%$ \\
\hline Synergy ${ }^{37}$ & Biodegradable & $\mathrm{Pt}-\mathrm{Cr}$ & $74-81$ & $\begin{array}{l}\text { Prospective all-comers study } \\
\text { registry (Asian population) }\end{array}$ & $4.2 \%$ TLF & $0.40 \%$ & $0.80 \%$ & $0.30 \%$ \\
\hline Ultimaster ${ }^{38}$ & Biodegradable & $\mathrm{Co}-\mathrm{Cr}$ & 80 & CENTURY study & $2.9 \% \mathrm{TLF}$ & $1.90 \%$ & $1.90 \%$ & $0.95 \%$ \\
\hline Orsiro ${ }^{39}$ & Biodegradable & $\mathrm{Co}-\mathrm{Cr}$ & $60-80$ & BIOFLOW-II trial & $3.1 \% \mathrm{TLF}$ & $1.00 \%$ & $2.35 \%$ & 0 \\
\hline Excel $2^{35}$ & Biodegradable & $\mathrm{Co}-\mathrm{Cr}$ & 88 & $\begin{array}{l}\text { Pooled } \\
\text { analysis of CREDIT-II and } \\
\text { CREDIT-III trials }\end{array}$ & $\begin{array}{l}5.0 \% \\
\text { TLF }\end{array}$ & $4.90 \%$ & $0.10 \%$ & - \\
\hline Firebird $2^{40}$ & Durable & $\mathrm{Co}-\mathrm{Cr}$ & 86 & FOCUS registry & $1.8 \%$ MACE & - & $0.95 \%$ & $0.60 \%$ \\
\hline $\begin{array}{l}\text { Promus } \\
\text { Element }^{41}\end{array}$ & Durable & $\mathrm{Pt}-\mathrm{Cr}$ & $81-86$ & EVOLVE trial & $3.1 \%$ TLF & $3.10 \%$ & 0 & 0 \\
\hline Xience ${ }^{36}$ & Durable & $\mathrm{Co}-\mathrm{Cr}$ & 81 & X-SEARCH registry & $9.2 \% \mathrm{MACE}$ & - & - & $0.60 \%$ \\
\hline
\end{tabular}

Abbreviations: DES, drug eluting stent; TLF, target-lesion failure; MACE, major adverse cardiac event; TLR, target-lesion revascularization; MI, myocardial infarction; ST, stent thrombosis; Co-Cr, cobalt-chromium; Pt-Cr, platinum-chromium.

observational registry. Second, there was no direct headto-head comparison with similar or other types of stents that might have resulted in superiority or noninferiority of the Tetriflex SES. Third, the registry reported 6-month follow-up results. However, long-term follow-up should be reported in future to establish its complete safety and effectiveness. Finally, the duration of dual-antiplatelet therapy remains unknown at follow-up, which might have some clinical relevance.

\section{Conclusion}

Altogether, the Tetriflex SES can be considered safe and effective in real-world patients, as it has displayed acceptable and positive clinical outcomes at 6-month follow-up, with low incidence of TLR and stent thrombosis. Future follow-up will further clear the picture for use of the Tetriflex SES in real-world scenarios, as polymers degrade completely within 12 months of stent implantation.

Supplementary Video 1 Pre-stent deployment: severely tortuous right coronary artery and lesion in posterior descending artery with $80 \%$ stenosis.

Supplementary Video 2 Stent deployment: $2.50 \times 24 \mathrm{~mm}$ Tetriflex stent negotiated in right coronary artery- posterior descending artery.

Supplementary Video 3 Post-stent deployment TIMI III flow.

\section{Abbreviations}

ARC, Academic Research Consortium; CAD, coronary artery disease; Co-Cr, cobalt-chromium; DES, drug-eluting stent; LDZ-link, long dual Z-link; MI, myocardial infarction; SES, sirolimus eluting stent; TLR, target-lesion revascularization.

\section{Author Contributions}

PA: conception and design of registry, data interpretation, critical revision for important intellectual content, involved in appropriate investigation of the work. RP: conception and design of the registry, critically revising it for important intellectual content, involved in appropriate investigation of the work. KC: data acquisition/data analysis and interpretation, drafting the article, involved in appropriate investigation of the work. SM: conception and design of the registry, critically revising it for important intellectual content, involved in appropriate investigation of the work. PJ: conception and design of the registry; data acquisition/data analysis and interpretation, drafting the article. VV and VV: conception and design of the registry, data acquisition/data analysis and interpretation, drafting the article, involved in appropriate investigation of the work. All authors gave final approval of the version to be published and agree to be accountable for all aspects of the work.

\section{Disclosure}

The authors report no conflicts of interest in this work. 


\section{References}

1. Morice MC, Serruys PW, Sousa JE, et al. A randomized comparison of a sirolimus-eluting stent with a standard stent for coronary revascularization. N Engl J Med. 2002;346(23):1773-1780. doi:10.1056/NEJMoa012843

2. Stone GW, Ellis SG, Cox DA, et al. A polymer-based, paclitaxeleluting stent in patients with coronary artery disease. $N$ Engl $\mathrm{J} \mathrm{Med}$. 2004;350(3):221-231. doi:10.1056/NEJMoa032441

3. Stettler C, Wandel S, Allemann S, et al. Outcomes associated with drugeluting and bare-metal stents: a collaborative network meta-analysis. Lancet. 2007;370(9591):937-948. doi:10.1016/S0140-6736(07)61444-5

4. Räber L, Kelbæk H, Ostojic M, et al. Effect of biolimus-eluting stents with biodegradable polymer vs bare-metal stents on cardiovascular events among patients with acute myocardial infarction: the COMFORTABLE AMI randomized trial. JAMA. 2012;308(8):777787. doi:10.1001/jama.2012.10065

5. Virmani R, Guagliumi G, Farb A, et al. Localized hypersensitivity and late coronary thrombosis secondary to a sirolimus-eluting stent: should we be cautious? Circulation. 2004;109(6):701-705. doi:10.1161/01. CIR.0000116202.41966.D4

6. Garg S, Bourantas C, Serruys PW. New concepts in the design of drug-eluting coronary stents. Nat Rev Cardiol. 2013;10(5):248. doi: $10.1038 /$ nrcardio.2013.13

7. Kolandaivelu K, Swaminathan R, Gibson WJ, et al. Stent thrombogenicity early in high-risk interventional settings is driven by stent design and deployment and protected by polymer-drug coatings. Circulation. 2011:123(13):1400-1409. CIRCULATIONAHA. 110.003210.

8. Brancati MF, Burzotta F, Trani C, Leonzi O, Cuccia C, Crea F. Coronary stents and vascular response to implantation: literature review. Pragmat Obs Res. 2017;8:137. doi:10.2147/POR.S132439

9. Burzotta F, Trani C, Todaro D, et al. Outcome of patients treated by a novel thin-strut cobalt-chromium stent in the drug-eluting stent era: results of the SKICE (Skylor in real world practice) registry. Catheter Cardiovasc Interv. 2009;73(4):457-465. doi:10.1002/ccd.21882

10. Hagemeister J, Baer FM, Schwinger RH, Höpp HW. Compliance of a cobalt chromium coronary stent alloy-the COVIS trial. Curr Control Trials Cardiovasc Med. 2005;6(1):17. doi:10.1186/1468-6708-6-17

11. Bax JJ, Baumgartner $\mathrm{H}$, Ceconi C, et al. Third universal definition of myocardial infarction. J Am Coll Cardiol. 2012;60(16):1581-1598. doi:10.1016/j.jacc.2012.08.001

12. Cutlip DE, Windecker S, Mehran R, et al. Clinical end points in coronary stent trials: a case for standardized definitions. Circulation. 2007;115 (17):2344-2351. doi:10.1161/CIRCULATIONAHA.106.685313

13. Kitabata H, Kubo T, Komukai K, et al. Effect of strut thickness on neointimal atherosclerotic change over an extended follow-up period ( $\geq 4$ years) after bare-metal stent implantation: intracoronary optical coherence tomography examination. Am Heart J. 2012;163(4):608616. doi:10.1016/j.ahj.2012.01.007

14. Bangalore S, Toklu B, Patel N, Feit F, Stone GW. Newer-generation ultrathin strut drug-eluting stents versus older second-generation thicker strut drug-eluting stents for coronary artery disease: metaanalysis of randomized trials. Circulation. 2018;138(20):2216-2226. doi:10.1161/CIRCULATIONAHA.118.034456

15. Smits PC, Hofma S, Togni M, et al. Abluminal biodegradable polymer biolimus-eluting stent versus durable polymer everolimus-eluting stent (COMPARE II): a randomised, controlled, non-inferiority trial. Lancet. 2013;381(9867):651-660. doi:10.1016/S0140-6736(12)61852-2

16. Palmerini T, Biondi-Zoccai G, Della Riva D, et al. Clinical outcomes with bioabsorbable polymer-versus durable polymer-based drug-eluting and bare-metal stents: evidence from a comprehensive network meta-analysis. J Am Coll Cardiol. 2014;63(4):299-307. doi:10.1016/j.jacc.2013.09.061

17. Lemos PA, Chandwani P, Saxena S, et al. Clinical outcomes in 995 unselected real-world patients treated with an ultrathin biodegradable polymer-coated sirolimus-eluting stent: 12-month results from the FLEX Registry. BMJ Open. 2016;6(2):e010028. doi:10.1136/bmjopen-2015010028
18. Raungaard B, Jensen L, Tilsted H, et al. Scandinavian Organization for Randomized Trials with Clinical Outcome (SORT OUT). Zotarolimus-eluting durable-polymer-coated stent versus a biolimuseluting biodegradable-polymer-coated stent in unselected patients undergoing percutaneous coronary intervention (SORT OUT VI): a randomised non-inferiority trial. Lancet. 2015;385(9977):1527-1535. doi:10.1016/S0140-6736(14)61794-3

19. Iantorno M, Lipinski MJ, Garcia-Garcia HM, et al. Meta-analysis of the impact of strut thickness on outcomes in patients with drugeluting stents in a coronary artery. Am J Cardiol. 2018. doi:10. 1016/j.amjcard.2018.07.040

20. Kim BK, Yoon JH, Shin DH, et al. Prospective and systematic analysis of unexpected requests for non-cardiac surgery or other invasive procedures during the first year after drug-eluting stent implantation. Yonsei Med J. 2014;55(2):345-352. doi:10.3349/ymj. 2014.55.2.345

21. Kastrati A, Mehilli J, Dirschinger J, et al. Intracoronary stenting and angiographic results: strut thickness effect on restenosis outcome (ISAR-STEREO) trial. Circulation. 2001;103(23):2816-2821. doi:1 0.1161/01.cir.103.23.2816

22. Ürgen Pache J, Kastrati A, Mehilli J, et al. Intracoronary stenting and angiographic results: strut thickness effect on restenosis outcome (ISAR-STEREO-2) trial. J Am Coll Cardiol. 2003;41(8):12831288. doi:10.1016/s0735-1097(03)00119-0

23. Morton AC, Crossman D, Gunn J. The influence of physical stent parameters upon restenosis. Pathologie Biologie. 2004;52(4):196205. doi:10.1016/j.patbio.2004.03.013

24. Koskinas KC, Chatzizisis YS, Antoniadis AP, Giannoglou GD. Role of endothelial shear stress in stent restenosis and thrombosis: pathophysiologic mechanisms and implications for clinical translation. $J$ Am Coll Cardiol. 2012;59(15):1337-1349. doi:10.1016/j.jacc.2011. 10.903

25. Joner M, Finn AV, Farb A, et al. Pathology of drug-eluting stents in humans: delayed healing and late thrombotic risk. $\mathrm{J} \mathrm{Am} \mathrm{Coll} \mathrm{Cardiol.}$ 2006;48(1):193-202. doi:10.1016/j.jacc.2006.03.042

26. Mehilli J, Byrne RA, Wieczorek A, et al. Randomized trial of three rapamycin-eluting stents with different coating strategies for the reduction of coronary restenosis. Eur Heart J. 2008;29(16):19751982. doi:10.1093/eurheartj/ehn253

27. Byrne RA, Kastrati A, Kufner S, et al. Randomized, non-inferiority trial of three limus agent-eluting stents with different polymer coatings: the Intracoronary Stenting and Angiographic Results: test Efficacy of 3 Limus-Eluting Stents (ISAR-TEST-4) trial. Eur Heart J. 2009;30(20):2441-2449. doi:10.1093/eurheartj/ehp352

28. Chevalier B, Silber S, Park SJ, et al. Randomized comparison of the Nobori Biolimus A9-eluting coronary stent with the Taxus Liberte paclitaxel-eluting coronary stent in patients with stenosis in native coronary arteries: the NOBORI 1 trial-phase 2. Circ Cardiovasc Interv. 2009;2(3):188-195. doi:10.1161/CIRCINTERVENTIONS. 108.823443

29. Stefanini GG, Byrne RA, Serruys PW, et al. Biodegradable polymer drug-eluting stents reduce the risk of stent thrombosis at 4 years in patients undergoing percutaneous coronary intervention: a pooled analysis of individual patient data from the ISAR-TEST 3, ISARTEST 4, and LEADERS randomized trials. Eur Heart J. 2012;33 (10):1214-1222. doi:10.1093/eurheartj/ehs086

30. Kang SH, Park KW, Kang DY, et al. Biodegradable-polymer drugeluting stents vs. bare metal stents vs. durable-polymer drug-eluting stents: a systematic review and Bayesian approach network metaanalysis. Eur Heart J. 2014;35(17):1147-1158. doi:10.1093/eurheartj/eht570

31. Zhu L, Lv YN, Wang LY. Stent thrombosis with biodegradable polymer drug-eluting stents versus durable polymer sirolimus-eluting stents: an update meta-analysis. Cardiology. 2015;130(2):96-105. doi: $10.1159 / 000368073$ 
32. Yang Y, Lei J, Huang W, Lei H. Efficacy and safety of biodegradable polymer sirolimus-eluting stents versus durable polymer drug-eluting stents: a meta-analysis of randomized trials. Int $J$ Cardiol. 2016;222:486-493. doi:10.1016/j.ijcard.2016.07.279

33. Navarese EP, Kubica J, Castriota F, et al. Safety and efficacy of biodegradable vs. durable polymer drug-eluting stents: evidence from a meta-analysis of randomised trials. EuroIntervention. 2011. doi:10.4244/EIJV7I8A155

34. Yin Y, Zhang Y, Zhao X. Safety and efficacy of biodegradable drug-eluting vs. bare metal stents: a meta-analysis from randomized trials. PLoS One. 2014;9(6):e99648. doi:10.1371/journal. pone.0099648

35. Wang G, Wang H, Xu B, et al. Efficacy and safety of a biodegradable polymer Cobalt-Chromium sirolimus-eluting stent (EXCEL2) in treating de novo coronary artery disease: A pooled analysis of the CREDIT II and CREDIT III trials. Catheter Cardiovasc Interv. 2017;89(S1):512-519. doi:10.1002/ccd.26887

36. Onuma Y, Kukreja N, Piazza N, et al. The everolimus-eluting stent in real-world patients: 6-month follow-up of the X-SEARCH (Xience V Stent Evaluated at Rotterdam Cardiac Hospital) registry. J Am Coll Cardiol. 2009;54(3):269-276. doi:10.1016/j.jacc.2009.05.016
37. Ananthakrishna R, Kristanto W, Liu L, et al. Incidence and predictors of target lesion failure in a multiethnic Asian population receiving the SYNERGY coronary stent: A prospective all-comers registry. Catheter Cardiovasc Interv. 2018. doi:10.1002/ccd.27577

38. Barbato E, Salinger-Martinovic S, Sagic D, et al. A first-in-man clinical evaluation of Ultimaster, a new drug-eluting coronary stent system: CENTURY study. EuroIntervention. 2015;11(5):541-548. doi:10.4244/EIJY14M08_06

39. Hideo-Kajita A, Garcia $\overline{H G}$, Azizi V, et al. Comparison of clinical outcomes between magmaris (DREAMS 2G) and orsiro drug eluting stents: pooled patient level analysis from biosolve II-III and bioflow II trials. J Am Coll Cardiol. 2018;71(11 Supplement):A1109. doi:10.1016/ S0735-1097(18)31650-4

40. Ge JB, Zhang F, Qian JY, Ge L, Liu XB, Zhou J. Six-month clinical outcomes of Firebird 2TM sirolimus-eluting stent implantation in real-world patients with coronary artery diseases. Chin Med J. 2011;124(6):831-835.

41. Meredith IT, Verheye S, Dubois CL, et al. Primary endpoint results of the EVOLVE trial: a randomized evaluation of a novel bioabsorbable polymer-coated, everolimus-eluting coronary stent. $\mathrm{J} \mathrm{Am} \mathrm{Coll}$ Cardiol. 2012;59(15):1362-1370. doi:10.1016/j.jacc.2011.12.016

\section{Publish your work in this journal}

Vascular Health and Risk Management is an international, peerreviewed journal of therapeutics and risk management, focusing on concise rapid reporting of clinical studies on the processes involved in the maintenance of vascular health; the monitoring, prevention and treatment of vascular disease and its sequelae; and the involvement of metabolic disorders, particularly diabetes. This journal is indexed on PubMed Central and MedLine. The manuscript management system is completely online and includes a very quick and fair peerreview system, which is all easy to use. Visit http://www.dovepress. com/testimonials.php to read real quotes from published authors. 